\title{
A review of tuberculous meningitis in a Canadian pediatric hospital
}

\author{
LISSETte NAVAS, MD, ELAINE WANG, MD, CM
}

\begin{abstract}
L NaVAS, E WANG. A review of tuberculous meningitis in a Canadian pediatric hospital. Can J Infect Dis 1991;2(4):155-160. Tuberculous meningitis is a disease associated with high morbidity and mortality. Experience with this disease at the Hospital for Sick Children in Toronto was reviewed to determine whether changes in prognosis have occurred in the past decade. All patients from whom the organism was recovered from the cerebrospinal fluid, or who had a positive Mantoux test in association with a compatible history, were included. Thirteen patients were identified from 1978 to 1989. The median age was six years (range 11 months to 17.5 years). Nine patients were born in Canada, but all except one were members of recently immigrant families. History of close contact with an adult with tuberculosis, or travel to an endemic area in the preceding six months, was present in seven cases. All patients had clinical manifestations and mild pleocytosis with elevated protein content in the cerebrospinal fluid. Patients were all diagnosed within 20 days after admission (median one day). Computed tomography scan of the head was abnormal in all patients within three weeks of admission. No patient died, although long term sequelae developed in five. The prognosis of tuberculous meningitis has improved in the past decade. Although a specific reason for this improvement cannot be definitively stated, earlier diagnosis and better chemotherapy may contribute.
\end{abstract}

Key Words: Children, Computed tomography scan, Tuberculous meningitis

\section{Revue des cas de méningite fuberculeuse dans un hôpital pédiatrique canadien}

RESUME: La méningite tuberculeuse est une maladie associée à une morbidité et à une mortalité élevées. L'expérience à cet égard du Hospital for Sick Children de Toronto a été examinée afin de déterminer les changements éventuels de pronostic qui seraient survenus au cours des dix dernières années. Ont été inclus tous les patients dans le liquide céphalorachidien de qui l'organisme avait été isolé ou chez qui le test de Mantoux avait donné des résultats positifs et dont les antécédents semblaient autoriser un diagnostic positif. Treize

Division of Infectious Disease, Department of Pediatrics, The Hospital for Sick Children; and Faculty of Medicine, University of Toronto, Toronto, Ontario

Correspondence and reprints: Dr Elaine Wang, Clinical Epidemiology Unit, The Hospital for Sick Children, 555 University

Avenue, Toronto, Ontario M5G 1X8. Telephone (416) 597-1500 ext 4783

Received for publication November 8, 1990. Accepted April 24, 1991 
patients ont été identifiés de 1978 à 1989. L’âge moyen était de six ans, et les deux extrêmes de 11 mois et de 17,5 ans. Neuf patients étaient natifs du Canada mais tous, à l'exception d'un seul, appartenaient à des familles nouvellement immigrées. Un contact avec un adulte tuberculeux ou un voyage dans une zone endémique au cours des six mois précédents a été rapporté dans sept cas. Tous les patients présentaient des symptômes cliniques et une faible pléocytose avec une protéinorachie élevée. Le diagnostic a été posé chez tous les patients en moins de 20 jours après leur admission (en un jour en moyenne). La tomodensitométrie du crâne était anormale chez tous les patients dans les trois semaines de leur hospitalisation. Aucun des patients n'est décédé mais la maladie a laissé des séquelles durables chez cinq d'entre eux. Le pronostic de la méningite tuberculeuse s'est amélioré au cours des dix dernières années. Bien qu'il soit difficile de connaitre la raison exacte de cette évolution favorable, il semblerait qu'un diagnostic plus rapide et une meilleure chimiothérapie y contribuent.

M ENINGITIS IS THE MOST SERIOUS COMPLICATION OF tuberculosis in children. Its incidence has decreased but sporadic cases continue to occur. Tuberculous meningitis represented 3.3\% of all tuberculosis in the United States in children younger than 15 years of age (1).

In Canada, 66 cases of tuberculous meningitis in patients younger than 19 years of age were reported between 1979 and 1986. Seventeen of these were reported in the province of Ontario (2). Case fatality rates ranging from 6 to 56\% and rates of sequelae in 15 to $63 \%$ of subjects have been observed (3-10). Delay in diagnosis, age younger than four years, and miliary tuberculosis have been associated with higher morbidity and mortality $(3,4,7,9,10)$.

The present study was conducted in order to: describe the characteristics of patients with tuberculous meningitis in a tertiary care North American hospital; and to determine whether a reduction in mortality and sequelae has occurred with the advent of new neurodiagnostic imaging techniques or therapy.

\section{PATIENTS AND METHODS}

The charts of all cases with tuberculous meningitis as the discharge diagnosis from the Hospital for Sick Children in Toronto between 1978 and 1989 were reviewed. This tertiary care hospital is the pediatric referral centre for central Ontario. To ensure identification of all cases, all Mycobacterium tuberculosis isolates from cerebrospinal fluid in the microbiology department were also reviewed for the same time period. A standardized form was used to abstract information on demographic characteristics, history of previous exposure, history of BCG vaccination, underlying conditions, symptom duration prior to admission, signs and symptoms, diagnostic methods, duration of therapy, side effects of therapy, and presence of sequelae on long term follow-up. Since 1979, all patients with bacterial meningitis have been followed at the infectious disease clinic for at least one year. All patients have undergone audiological, psychological and neurological assessments (11).

Patients were classified according to the

TABLE 1

Demographics of 13 patients with tuberculous meningitis

\begin{tabular}{|c|c|c|c|c|c|c|c|}
\hline Case & $\begin{array}{c}\text { Year of } \\
\text { diagnosis }\end{array}$ & Sex & Age & Parents' birthplace & $\begin{array}{l}\text { Born in } \\
\text { Canada }\end{array}$ & TB contact & $\begin{array}{c}\text { Travel within six } \\
\text { months }\end{array}$ \\
\hline 1 & 1980 & Male & 11 months & Phillipines & + & + & - \\
\hline 2 & 1983 & Male & 15 months & Korea & + & + & - \\
\hline 3 & 1987 & Female & 17 months & Portugal & + & - & - \\
\hline 4 & 1986 & Male & 18 months & Dominican Republic & + & - & + \\
\hline 5 & 1982 & Female & 22 months & Yugoslavia & + & - & + \\
\hline 6 & 1983 & Female & 3 years & India & + & + & + \\
\hline $7^{*}$ & 1988 & Female & 6 years & Canada & + & - & - \\
\hline 8 & 1985 & Male & 6 years & India & + & - & - \\
\hline 9 & 1989 & Male & 12 years & India & + & - & - \\
\hline $10^{\dagger}$ & 1986 & Male & 13 years & Phillipines & - & - & - \\
\hline 11 & 1981 & Female & 15 years & Phillipines & - & + & - \\
\hline 12 & 1985 & Female & 16 years & Korea & - & - & + \\
\hline 13 & 1982 & Male & 17.5 years & Vietnam & - & - & - \\
\hline
\end{tabular}

'Patient with acute lymphocytic leukemia; 'Patient with bone marrow transplant 
TABLE 2

Symptoms and signs on admission of 13 patients with tuberculous meningitis

\begin{tabular}{llll}
\hline Symptom & $\mathbf{n}(\%)$ & Symptom & $\mathbf{n}(\%)$ \\
\hline Lethargy & $9(69)$ & Fever & $13(100)$ \\
Vomiting & $9(69)$ & Meningismus & $10(77)$ \\
Headache & $8(61)$ & Drowsiness & $5(38)$ \\
Irritability & $5(38)$ & Seizures & $4(30)$ \\
Poor appetite & $5(38)$ & Cranial nerve palsy & $2(15)$ \\
Photophobia & $4(30)$ & Papilledema & $1(7)$ \\
Weight loss & $2(15)$ & Hemiparesis & $1(7)$ \\
Night sweating & $2(15)$ & Decreased level of & $2(15)$ \\
Blurred vision & $1(7)$ & consciousness & \\
\hline
\end{tabular}

scheme described by Gutman (12). Stage 1 is characterized by general symptoms of an infectious process without evidence of neurological involvement. In stage 2 , there is neurological involvement with meningeal signs or symptoms of encephalitis, and in stage 3, there are profound neurological and sensorial changes (unresponsiveness) present on admission.

All cerebrospinal fluid specimens were examined within $15 \mathrm{~h}$ of receipt in the bacteriology laboratory. Cerebrospinal fluid obtained between 09:00 and 17:00 was examined immediately. Cerebrospinal fluid obtained outside of those hours was placed in an incubator at $37^{\circ} \mathrm{C}$ until examination the following morning. Until 1988 cerebrospinal fluid was stained using Ziehl-Neelsen stain to identify the presence of acid-fast bacilli (13). Since 1988 it has been replaced by Kinyoun acid-fast stain (13). All cerebrospinal fluid specimens were sent to the provincial health laboratory in Toronto where they were stained using auramine-rhodamine stain (13) and inoculated onto Lowenstein-Jensen media. The cultures were maintained for eight weeks if the initial smear was negative and for 12 weeks if the smear was positive (14).

Tuberculous meningitis was diagnosed if the cerebrospinal fluid smear or culture was positive for $M$ tuberculosis or when clinical manifestations and cerebrospinal fluid findings were consistent with tuberculous meningitis and at least two of the following were present $(3,6)$ : chest radiograph findings compatible with tuberculosis (diffuse interstitial infiltrates, hilar lymphadenopathy, calcified lymph nodes); head computed tomography scan compatible with tuberculous meningitis (hydrocephalus, infarcts, meningeal enhancement); recovery of $M$ tuberculosis from gastric aspirate, sputum, urine or other site; tuberculin skin test reaction of $10 \mathrm{~mm}$ induration or greater after intradermal administration of five tuberculous units of purified protein derivative (15); and/or
TABLE 3

Cerebrospinal fluid findings in 13 cases of tuberculous meningitis

\begin{tabular}{ll}
\hline & $\mathrm{n}(\%)$ \\
\hline White blood cell count (cells $/ \mathrm{mm}^{3}$ ) & \\
10 to 99 & $5(38)$ \\
100 to 399 & $7(54)$ \\
$>400$ & $1(7)$ \\
Lymphocytes $(\%)$ & \\
25 to 50 & $1(7)$ \\
51 to 75 & $5(38)$ \\
$>75$ & $6(46)$ \\
Protein $(\mathrm{g} / \mathrm{L})$ & \\
0.5 to 1.0 & $7(54)$ \\
1.1 to 3.0 & $5(38)$ \\
Glucose $(\mathrm{mmol} / \mathrm{L})$ & \\
$<1.5$ & $4(30)$ \\
1.51 to 2.5 & $8(61)$ \\
2.51 to 3.5 & $1(7)$ \\
Positive Ziehl-Neelsen stain & $3(23)$ \\
\hline
\end{tabular}

family contact with tuberculosis identified in the preceding year.

\section{RESULTS}

Thirteen cases of tuberculous meningitis were identified. The demographic characteristics are summarized in Table 1 . Seven were males. The median age was six years (range 11 months to 17.5 years). Nine patients were born in Canada, but all children except one were members of immigrant families. The distribution of the children's ethnic groups is displayed in Table 1. All patients studied were from Toronto except for one transferred from the city of Trenton.

One patient was documented to have received $\mathrm{BCG}$. Seven others had not received BCG. Information about BCG was not charted on five patients. Two patients had an underlying disease. One had acute lymphocytic leukemia and one had received a second bone marrow transplant for aplastic anemia two years prior to admission. One parent or grandparent of four of the patients had been diagnosed with pulmonary tuberculosis in the preceding year. Four patients were presumably exposed while abroad (India two, Dominican Republic one, Yugoslavia one). The number of days of symptoms prior to admission varied from three to 49 days (median nine). The number of days to diagnosis after admission varied from zero to 20 days (median one).

Table 2 lists the symptoms and signs described on admission. All patients were febrile, $77 \%$ had meningismus, 69\% had lethargy and vomiting, and $61 \%$ had headache. One patient was in stage 1,10 in stage 2 , and two in stage 3 , as defined by the Gutman classification (12).

Mantoux tests were positive in seven cases. One 


\section{TABLE 4}

Long term sequelae in 12 cases of tubercuolous meningitis

\begin{tabular}{ll}
\hline Sequelae & $\mathrm{n}(\%)$ \\
\hline Hydrocelphalus and VPS & $4(33)$ \\
Seizures & $2(17)$ \\
Bilateral mild hearing loss & $1(8)$ \\
Bilateral profound hearing loss & $1(8)$ \\
Severe mental retardation & $1(8)$ \\
Spastic diplegia & $1(8)$ \\
Hemiparesis & $1(8)$ \\
Mild optic atrophy & $1(8)$
\end{tabular}

of the Mantoux test positive patients had received BCG but had induration of greater than $20 \mathrm{~mm}$ with the skin test. A negative skin test was documented in four patients on admission; two had negative candida skin tests at the same time. Skin test results were not found on two patients.

Cerebrospinal fluid results (Table 3 ) at the time of admission showed mild pleocytosis which varied from 10 to 513 cells $/ \mathrm{mm}^{3}$ with a lymphocyte predominance in 11 of 13 . Elevated protein content (greater than $0.5 \mathrm{~g} / \mathrm{L}$ ) was observed in all 12 patients in whom it was ascertained.

Low glucose (less than $2.1 \mathrm{mmol} / \mathrm{L}$ ) was observed in nine subjects. Ziehl-Neelsen stain was positive in three cases (23\%), all of which were culture positive. $M$ tuberculosis was recovered from six patients: cerebrospinal fluid specimens (four), brain biopsy (one), gastric aspirates (three). All isolates were isoniazid sensitive.

All patients had chest radiographs on admission and six of these radiographs were compatible with tuberculosis. Three patients had miliary tuberculosis, one had middle lobe consolidation, one had hilar lymphadenopathy, and one had perihilar calcification. Two of the patients with miliary tuberculosis had permanent sequelae. One of these had come into hospital in stage 3.

Head computed tomography scan abnormalities were described in all 13 cases. Hydrocephalus or mild ventricular dilation was present in eight patients (61.5\%), of whom four required ventriculoperitoneal shunts. Other findings were tuberculomas in two cases, infarcts in two, and enhancement of subarachnoid space and basilar area in five. Scans were abnormal within the first week after admission in 10 cases. Two patients developed hydrocephalus two weeks after admission and another developed a tuberculoma three weeks after admission.

Ten patients completed one year of therapy. Two received 18 months of therapy. One of these patients was immunosuppressed; the other had severe disease. Duration of therapy was unknown in one patient who had moved to another province. Isoniazid and rifampin were included in the regimens of all patients. Two received these two agents alone, nine received three agents (streptomycin [six], ethambutol [two], pyrazinamide [one]) and two received four agents (streptomycin and pyrazinamide). Duration of the third or fourth drug varied from three to eight weeks.

In 11 of 13 patients, steroids had been used from two to four weeks with $50 \%$ of cases having completed four weeks.

Adverse drug effects were documented in five patients (38.4\%). These included mild transient increases in liver enzymes after two weeks of triple therapy, which required no changes in therapy. Hepatitis was present in three patients. In two cases, rifampin was discontinued, and in a third severe case, both rifampin and isoniazid were discontinued. Arthralgias and dizziness after two months on a four drug regimen were described in one patient. All manifestations subsided when antituberculous medications were discontinued. There were no side effects related to steroid therapy. The duration of hospitalization varied from two to 18 weeks.

Follow-up was obtained in 12 cases with a median of 16 months (range 12 to 24). All patients were followed at six weeks and three, six and 12 months after discharge. Five patients (38.4\%) had long term sequelae including four with hydrocephalus and ventriculoperitoneal shunt, two with seizures, two with hearing deficit, and two with motor deficits (Table 4). There were no deaths. One of two patients classified as Gutman stage 3 was severely incapacitated with hydrocephalus requiring a ventriculoperitoneal shunt, and resulting in left spastic diplegia and mental retardation. The other patient had profound bilateral hearing loss.

\section{DISCUSSION}

The optimal management of tuberculous meningitis is limited by difficulties in early diagnosis. Clinical manifestations are nonspecific, and diagnostic tests that are both sensitive and specific have yet to be developed. Thirteen patients diagnosed with tuberculous meningitis over 10 years at the Hospital for Sick Children in Toronto have been described. The demographic characteristics of this group clearly show a higher incidence in immigrants and younger patients. The median age of six years is older than in other reports in which patients younger than four years of age represented more than $50 \%$ of cases of tuberculous meningitis (3-9), and children younger than five years of age represented $60 \%$ of overall tuberculous disease (1). This difference in the present 
TABLE 5

Summary of morbidity and mortality of tuberculous meningitis observed in previous studies

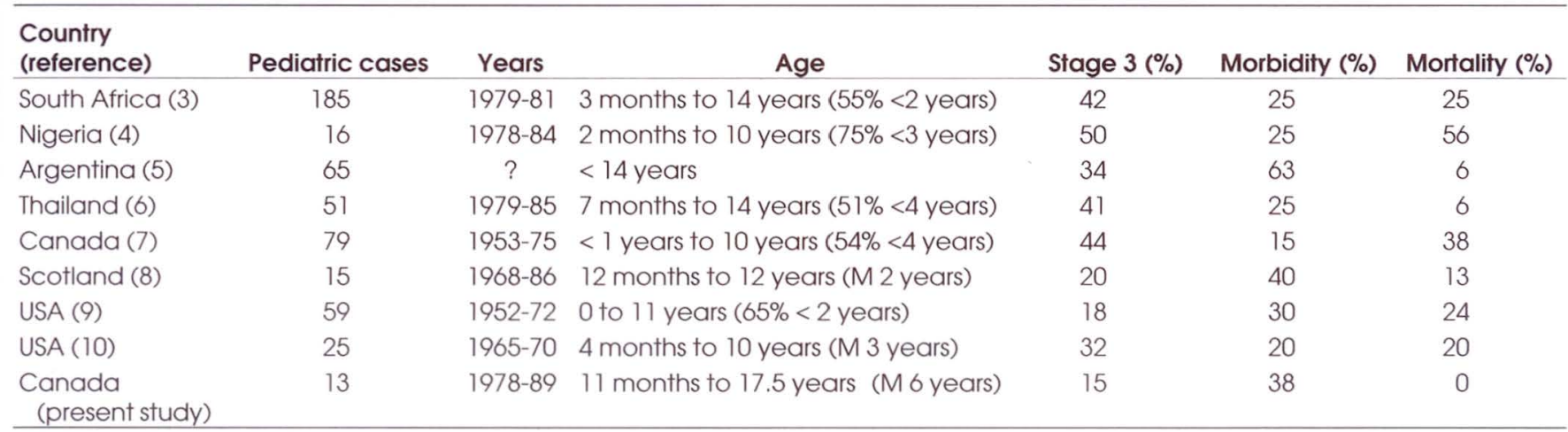

M Median

series may be related to the greater number of recent immigrants to this province. No difference in patient referral pattern was observed over the course of this study. Approximately two cases were seen annually from 1980 to 1989 . No cases were reported in 1978 or 1979 . There may be an upward trend in the province of Ontario because there were one or two cases each year, except in 1983 when there were five cases, and 1985 when there were four cases (2).

Early suspicion of tuberculous meningitis was based on ethnic origin, history of tuberculosis contact, and cerebrospinal fluid findings. A delay in diagnosis occurred in one patient with a history of acute lymphocytic leukemia who had no travel or contact history. Despite a characteristic cerebrospinal fluid profile, tuberculous meningitis was suspected only after a second computed tomography scan showed an intracranial mass consistent with tuberculoma, confirmed after brain biopsy.

Isolation of $M$ tuberculosis from cerebrospinal fluid was not a sensitive test, occurring in only $31 \%$ of cases, similar to observations in the literature $(7-9,11)$.

Head computed tomography scan has been used in the diagnosis of tuberculous meningitis since 1978 when the first case reports were published (16-18). The present observations of hydrocephalus, meningeal enhancement, infarcts and tuberculomas are similar to those reported in the literature $(16,17,19-21)$. Hydrocephalus has been associated with more serious disease (19), and in

\section{REFERENCES}

1. Snider DE, Rieder HL, Combs D, et al. Tuberculosis in children. Pediatr Infect Dis $\mathrm{J}$ 1988;7:271-8.

2. Canadian Centre for Health Information. Tuberculous Statistics. Catalog \# 82212, 1979-1986. Annual publication. Ottawa: Statistics Canada, 1988. a recent publication hydrocephalus was present in all children with tuberculous meningitis who underwent head computed tomography scans (20). Furthermore, computed tomography scans may be useful in following the course of tuberculomas during treatment (22) and in the initial assessment of children with suspected tuberculous meningitis $(20,21)$.

Initial triple therapy for two months, continued with isoniazid and rifampin for one year, was the most common regimen used in the present patients. An uncontrolled study from Thailand describes the efficacy of a two drug regimen (isoniazid and rifampin) for 12 months. No relapse was observed in that study (6). Hepatotoxicity with isoniazid and rifampin has been described in 3\% of pediatric patients with pulmonary tuberculosis (23), but the risk increases with severity of disease $(23,24)$. In the present review, $38 \%$ had side effects but only one case had severe hepatitis.

None of the patients reported in this study died. This contrasts with previous reports of the disease (Table 5). Comparison of present case fatality rate and sequelae with these studies will be difficult because of differences in stage of disease on admission, methods of diagnosis, drug regimens and follow-up. As more neurodiagnostic studies become available, the methods of diagnosing tuberculous meningitis will change. The importance of clinical suspicion, especially with a characteristic cerebrospinal fluid profile, must be emphasized. The prognosis of tuberculous meningitis treated in a North American hospital has improved.

3. Deeny J, Walker MJ, Kibel MA, et al. Tuberculous meningitis in children in the Western Cape. S Afr Med J 1985;68:75-8.

4. Taqi AM, Anene EN, Naida AM. Tuberculous meningitis in children at Zaria, Nigeria: A review of 16 cases. Public Health 1986;100:242-7.

5. Leiguarda R, Berthier M, Starkstein S, et al. Ischemic infarction in 25 children with 
tuberculous meningitis. Stroke 1988;19:200-4.

6. Visudhiphan P, Chiemchanya S. Tuberculous meningitis in children: Treatment with isoniazid and rifampin for twelve months. J Pediatr 1989;114:875-9.

7. Delage G, Dusseault M. Tuberculous meningitis in children: A retrospective study of 79 patients, with an analysis of prognostic factors. Can Med Assoc J 1979;120:305-9.

8. Galea P, Goel KM. Tuberculous meningitis in children: A review of 15 cases. Scot Med J 1988;33:205-7.

9. Sumaya C, Simek M, Smith M, et al. Tuberculous meningitis in children during the isoniazid era. J Pediatr 1975;87:43-9.

10. Steiner P, Portugaleza C. Tuberculous meningitis in children. Am Rev Respir Dis 1973;107:22-9.

11. Jadavji T, Biggar WD, Gold R, et al. Sequelae of bacterial meningitis in children treated for seven days. Pediatrics 1986;78:21-5.

12. Krugman S, Katz SL, Gershon AA, Wilfert CM. Tuberculosis. In: Krugman S, Katz SL, Gershon AA, Wilfert CM, eds. Textbook of Infectious Diseases in Children, 8th edn. St Louis: The CV Mosby Co, 1985:413-20.

13. Sommers HM, Good RC. Mycobacterium. In: Lennette EH, Balows A, Hausler WJ, Shadomy HJ, eds. Manual of Clinical Microbiology, 4th edn. Washington: American Society for Microbiology, 1985:223-30.

14. Center for Disease Control. Isolation and identification of $M$ tuberculosis. In: Department of Health and Human Services, ed. Center for
Disease Control Manual. Atlanta: 1981.

(publication \#8390)

15. Snider DE. The tuberculin skin test. Am Rev Respir Dis 1982;125:108-18.

16. Price HI, Danziger A. Computed tomography in cranial tuberculosis. Am J Roentgenol 1978;130:769-71.

17. Bhargava S, Gupta AK, Tandon N. Tuberculous meningitis: A CT study. Br J Radiol 1982;55: 189-96.

18. Chu NS. Tuberculous meningitis: Computerized tomographic manifestations. Arch Neurol 1980;37:458-60.

19. Teoh R, Humphries MJ, Hoare RD, et al. Clinical correlation of CT changes in 64 Chinese patients with tuberculous meningitis. J Neurol 1989;236:48-51.

20. Waecker NJ, Connor JD. Central nervous system tuberculosis in children: A review of 30 cases. Pediatr Infect Dis J 1990;9:539-43.

21. Gurses N, Ozkan A, Diren B. Tuberculous meningitis in childhood: Clinical and computerized tomography scan manifestations. Turk J Pediatr 1987;29:207-15.

22. Bagga A, Kalra V, Ghai OP. Intracranial tuberuloma. Clin Pediatr 1988;27:487-90.

23. O'Brien RJ, Long MW, Cross FS, et al. Hepatotoxicity from isoniazid and rifampin among children treated for tuberculosis. Pediatrics 1983;72:491-9.

24. Ramachandran P, Duraipandian M, Nagarajan M, et al. Three chemotherapy studies of tuberculous meningitis in children. Tubercle 1986;67:17-29. 


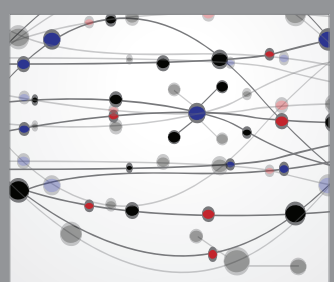

The Scientific World Journal
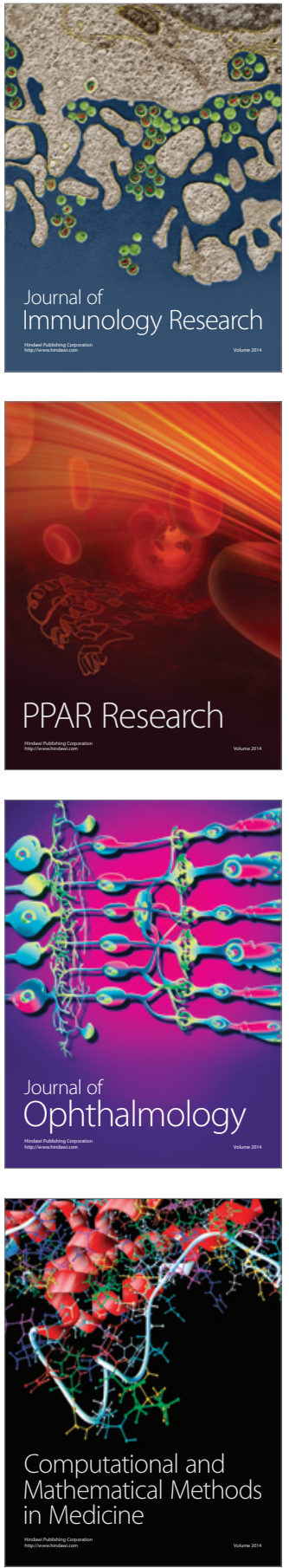

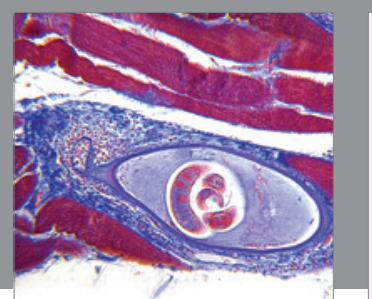

Gastroenterology Research and Practice

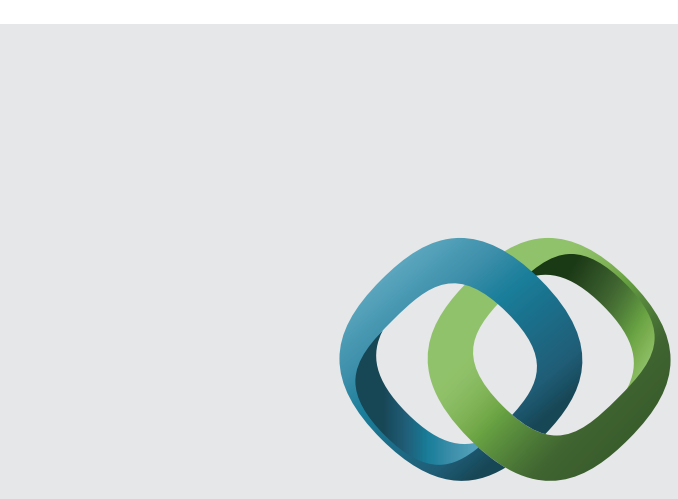

\section{Hindawi}

Submit your manuscripts at

http://www.hindawi.com
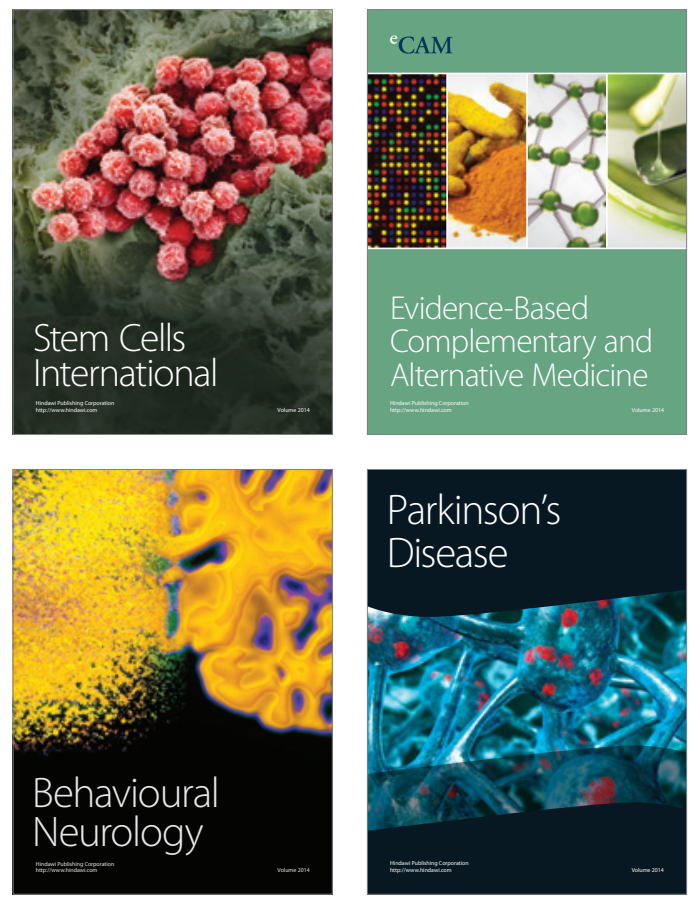
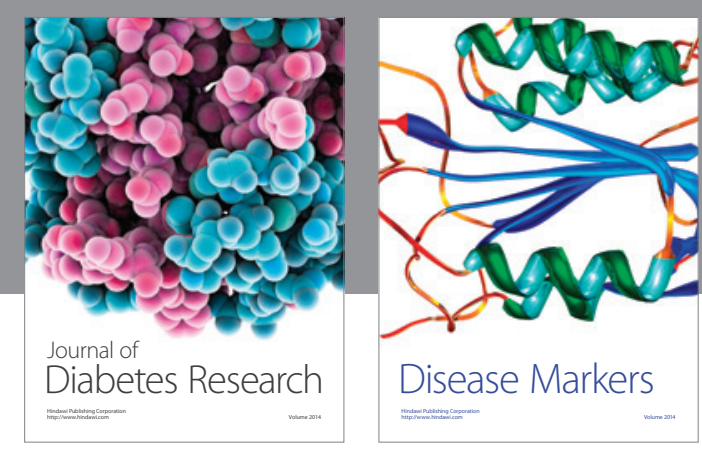

Disease Markers
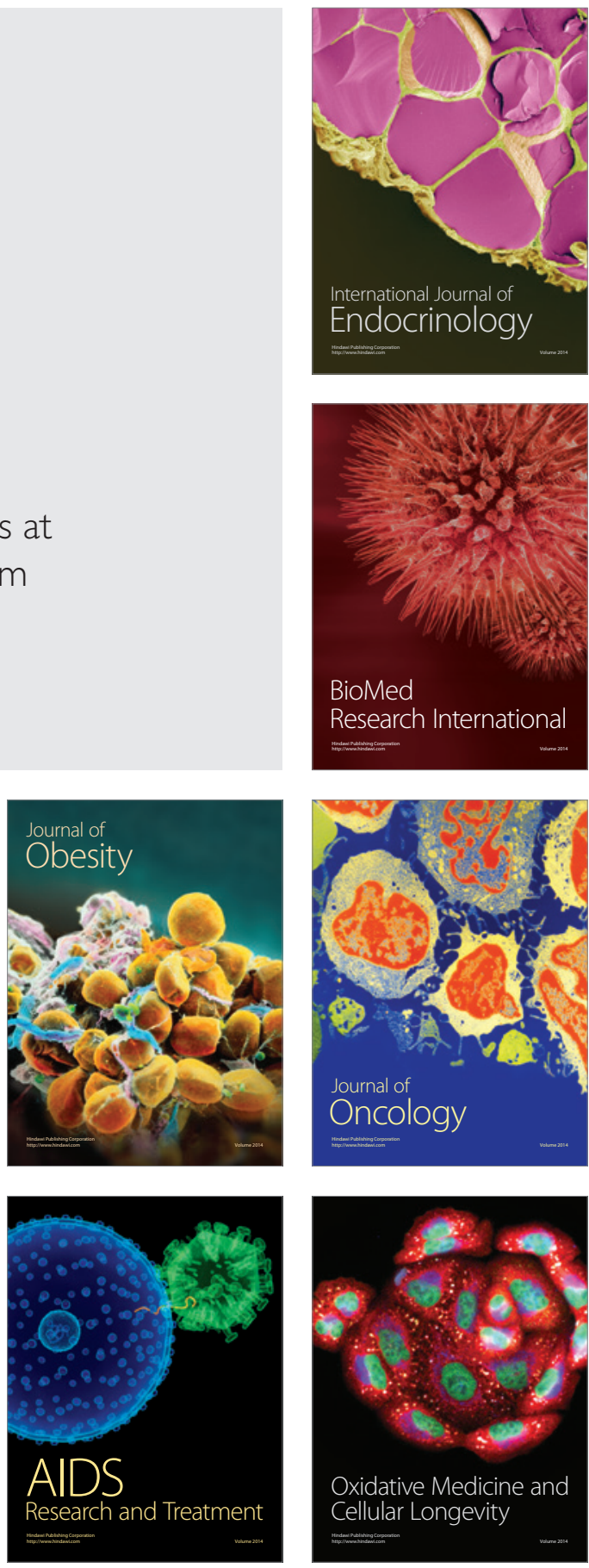